\title{
Assessment of the effectiveness of agricultural technologies based on production data
}

\author{
N.V. Stepnykh, S.D. Gilev, E.V. Nesterova* , A.M. Zargaryan, and S.A. Kopylova \\ FSBSI "Ural Federal Agrarian Scientific Research Centre, Ural Branch of the Russian Academy of \\ Sciences", 620142, Yekaterinburg, Belinskogo Str., 112A, Russia
}

\begin{abstract}
Modern agriculture is characterized by a variety of technologies associated with a multivariance of means of production. Due to the fact that the forces of scientific organizations do not allow to study most of the innovations in agriculture, the analysis of the effectiveness of technologies is possible directly in agricultural enterprises, where a large amount of agronomic and economic information obtained in the specific conditions of the introduction of agricultural practices is accumulated. The purpose of the study was to analyze the effectiveness of modern technologies for growing grain crops according to accounting and agronomic reports of agricultural enterprises of the Kurgan region. The methods of monographic, mathematical, and statistical analysis of data from literary sources, annual reports of agricultural enterprises of the region, as well as data from production fields of the Kurgan Research Institute of Agricultural Sciences were used. The results of the study showed the possibility of obtaining high results in crop production due to different methods of tillage (with and without surface tillage), the use of optimal doses of fertilizers. The reserves of profitability growth are associated with a more accurate use of resources, which is possible when considering the data of each field, thanks to the maintenance of electronic books of the field history, as a variant of a digital management tool in crop production.
\end{abstract}

\section{Introduction}

The diversity of agricultural technologies has increased significantly in recent decades due to a large assortment of agricultural machines, tools, fertilizers, plant protection products, varieties and hybrids of agricultural crops. The choice of effective technologies for a particular farm has become more difficult even for a trained specialist. Possession of new knowledge and its use in the analysis of primary production information is becoming increasingly important for the development of agricultural production. Information becomes the main resource of management, and providing enterprises with it is one of the main directions of the agro-industrial complex development, affecting material or energy resources, the result of production and the competitiveness of products $[1,2]$.

It is informatization, which is inextricably linked with digitalization, that is one of the main driving forces of agriculture development at the present stage. For high-quality and effective management based on information developments in agriculture, it is necessary to

* Corresponding author: kniish@ketovo.zaural.ru 
gradually introduce them into agricultural enterprises and form a developed information infrastructure on the scale of regions and the country $[3,4]$.

As a solution, scientists propose to build a single digital platform for the agro-industrial complex, which represents the integration of primary accounting and technological databases, storage and analysis of primary accounting, technological, and statistical information in a single cloud database (DB). At the same time, the primary accounting database, which is stored in the "cloud" of a typical site, should be able to be filled in by the operator from any mobile device. Some of the database fields could be filled in automatically with information from various sensors and devices [5, 6]. At the same time, options are proposed for developing an annual plan of an agricultural enterprise based on an economic and mathematical model of step-by-step optimization, including an assessment of the parameters of yield formation based on field history data, a plan for economically justified fertilization, considering the structure of crop rotation [7].

The relevance and necessity of such a unified database is acute and has been for a long time. It is the primary production data that is the basis of the information base for the adaptation and analysis of the effectiveness of agricultural technologies in local conditions.

In Soviet times, testing and evaluating the means of production in various conditions of the region was one of the tasks of the state agricultural science. At present time, for a number of reasons, scientific institutions are not able to study all new agricultural practices, preparations or innovations in different conditions. In addition, even the received scientific information on them is often found in miscellaneous sources [8]. Nevertheless, the work on assessing the economic efficiency of technologies in production is extremely important. At the same time, the information field of agricultural enterprises is not empty, economic activity is recorded annually, accounting and agronomic reports are compiled, which contain useful information and are provided to regional agricultural administrations, but are not used much to analyze the effectiveness of agricultural technologies. One of the options for obtaining new knowledge on the effectiveness of agricultural innovations is the analysis of these reports, which was one of the tasks of this study. The peculiarities of this data are that they are in different forms, transmitted through different channels, compiled and stored in different departments. Economic indicators are contained in accounting reports, which are collected only for agricultural organizations. Information about the technologies of growing agricultural crops is found in agronomic reports for all enterprises, including farmers. Accounting statements are mandatory, they are of high-quality, better verified, but there is no data on technologies in them. Agronomic reports lack economic information, so they do not allow for an economic assessment of agricultural practices. Nevertheless, this is the only source of such data on a regional scale.

The parameters of technologies in the district or in the region are generally similar, which allows them to be combined for a general analysis, and in farms to make decisions based on general recommendations, but in particular they differ, which requires individual design of farming systems and adaptation of technologies. Therefore, it is important to have a system for storing and analyzing production data in a specific production.

Our analysis of accounting and agronomic reports of agricultural enterprises for the production of spring wheat, as an example of the use of production data, was aimed at establishing the return on investment costs associated with intensification as the main direction for improving the efficiency of modern agriculture. Scientific and industrial experience has established that the intensification of production contributes to a significant increase in yield compared to extensive technologies - by 1.5-2 times, at the same time leads to an increase in costs, primarily for chemical means [9]. This has become especially evident in recent years against the background of the strengthening of the already existing disparity in prices for resources and products, which is confirmed both by research results 
in other regions [10] and by our analysis of grain production efficiency in the Kurgan region.

\section{Materials and methods}

The research was carried out in the Kurgan Research Institute of Agriculture - branch of the FSBSI UrFANITs Ural Branch of the Russian Academy of Sciences - in the laboratory of innovative development economy within the framework of the State Task of the Ministry of Science and Higher Education on the topic No. 0532-2021-0002 "To improve the system of adaptive landscape farming for the Ural region and create new-generation agricultural technologies based on minimizing soil treatment, crop rotation diversification, rational use of pesticides and biological products, preservation and improvement of soil fertility and to develop an information and analytical complex of computer programs that provides innovative management of the farming system". Monographic and statistical methods were used. To analyze the economic efficiency of technologies, data from accounting and agronomic reports of agricultural enterprises of the Kurgan region were used (Reports on production, costs, prime cost and sales of crop production for 2017-2020 in agricultural organizations of the Kurgan region, form No. 9-apk). The evaluation of the effectiveness of agricultural technologies is also given using production data from the book of the field history of the Kurgan Research Institute of Agricultural Sciences.

\section{Results and Discussion}

When analyzing the accounting reports, all enterprises were grouped into 4 groups according to the level of costs invested in production - from less to more (Table 1).

In 2017, in the first group, the cost per 1 ha of wheat sowing averaged 4,756 rubles, yield $1.2 \mathrm{t} / \mathrm{ha}$, cost $-3,970$ rubles/t, profitability $-132 \%$. In the 4 th group with costs almost 3 times higher (14,041 rubles/ha), the yield increased to $2.85 \mathrm{t} / \mathrm{ha}$, or 2.4 times, but this is less than the increase in costs. The lag in the growth of wheat yield from the growth of costs led to an increase in the cost of grain (4,920 vs. 3,970 rubles/ton) and a decrease in profitability (from 132 to $110 \%$ ). At the same time, due to the increase in yield, the profit increased: from 6,287 to 11,643 rubles/ha, which so far motivates farmers to invest in intensification.

In 2018, the average wheat yield for enterprises due to less favorable weather and phytosanitary conditions was lower than in $2017-1.76$ against $2.13 \mathrm{t} / \mathrm{ha}$, and, accordingly, economic efficiency indicators decreased. The pattern remained the same: in the 4th group of enterprises with intensive technologies, costs increased 3.1 times (from 4,793 to 14,911 rubles/ha), yield increased 2.4 times (from 0.96 to $2.34 \mathrm{t} / \mathrm{ha}$ ), but profit increased only 1.3 times (from 2,943 to 3,863 rubles/ha). The lag in the growth of wheat yield from the cost level led to an increase in the cost of grain $(6,380$ rubles/ton) and a decrease in profitability to $26 \%$.

Table 1. Economic efficiency of wheat production in agricultural organizations of the Kurgan region*, 2017-2020.

\begin{tabular}{|c|c|c|c|c|c|c|c|c|c|}
\hline $\begin{array}{c}\text { Enterpris } \\
\text { e group }\end{array}$ & $\begin{array}{c}\text { Costs, } \\
\text { rub/ha }\end{array}$ & $\begin{array}{c}\text { Yield, } \\
\text { t/ha }\end{array}$ & $\begin{array}{c}\text { Profit, } \\
\text { rub/ha }\end{array}$ & $\begin{array}{c}\text { Profitabilit } \\
\text { y, \% }\end{array}$ & $\begin{array}{c}\text { Enterpris } \\
\text { e group }\end{array}$ & $\begin{array}{c}\text { Costs, } \\
\text { rub/ha }\end{array}$ & $\begin{array}{c}\text { Yield, } \\
\text { t/ha }\end{array}$ & $\begin{array}{c}\text { Profit, } \\
\text { rub/ha }\end{array}$ & $\begin{array}{c}\text { Profitability } \\
, \%\end{array}$ \\
\hline \multicolumn{8}{|c|}{2017} \\
\hline 1 & 4756 & 1.20 & 6287 & 132 & 1 & 4793 & 0.96 & 2943 & 61 \\
\hline 2 & 6959 & 1.71 & 9050 & 130 & 2 & 7365 & 1.35 & 3515 & 48 \\
\hline 3 & 9312 & 2.10 & 11431 & 123 & 3 & 9481 & 1.55 & 2944 & 31 \\
\hline 4 & 14041 & 2.85 & 15464 & 110 & 4 & 14911 & 2.34 & 3863 & 26 \\
\hline \multicolumn{8}{|c|}{2019} & & \multicolumn{7}{c|}{2020} \\
\hline
\end{tabular}




\begin{tabular}{|c|c|c|c|c|c|c|c|c|c|}
\hline 1 & 5418 & 1.23 & 7196 & 133 & 1 & 6356 & 0.90 & 4394 & 69 \\
\hline 2 & 8800 & 1.52 & 6823 & 78 & 2 & 9154 & 1.13 & 4316 & 47 \\
\hline 3 & 11319 & 1.74 & 6565 & 58 & 3 & 12013 & 1.42 & 4875 & 41 \\
\hline 4 & 17419 & 2.56 & 8891 & 51 & 4 & 18083 & 1.68 & 1938 & 11 \\
\hline
\end{tabular}

* Calculated by the authors on the basis of annual production reports.

These trends continued in 2019, while the costs of grain production in the 4th group of enterprises increased even more due to rising prices - up to $26,310 \mathrm{rub} / \mathrm{ha}$. The higher average cost of grain at which farms sold products $(10,280 \mathrm{rub} /$ ton in 2019 against 8,030 $\mathrm{rub} /$ ton in 2018) allowed them to partially compensate and make a profit by $1,695 \mathrm{rub} / \mathrm{ha}$ more than in the first group, but the gap in the profitability of grain production in these groups increased (51\% in 4 th group against $132 \%$ in 1 st group).

The field season of 2020 was characterized as acutely arid (HTC for May-August 0.5, in 2017-2019 0.9-1.0), yield and economic indicators were significantly lower than in recent years. The profitability of production in the 4th group, where the costs averaged 18,083 $\mathrm{rub} / \mathrm{ha}$, fell to $11 \%$, the cost of obtaining an additional crop increase was not justified by its cost, for the first time in these years, the profit from 1 ha was lower compared to other groups.

On average, a clear trend has been noted for 4 years - a decrease in profitability with an increase in production costs. This indicates that at present the disparity of prices in the production of agricultural products has reached its critical limit and, in addition to state regulation, internal reserves are required to increase economic efficiency. To find them, agronomic reports were analyzed.

For example, data for 2019 for 153 agricultural enterprises were compared, which were divided into 3 groups according to the level of profitability of wheat production. Profitability depended on the yield of grain crops, the correlation coefficient (r) was 0.42 . Therefore, $82 \%$ is the share of other factors.

Of the analyzed factors, the yield of grain crops was significantly affected by the use of fertilizers, the correlation coefficient ( $r$ ) is 0.56 . Nevertheless, their impact on profitability was significantly less $(\mathrm{r}=0.16)$, which is due to the high price of fertilizers and insufficient payback by increasing the yield. Thus, the grouping of data on fertilizer doses showed an increase in profit and profitability of production from their use to a certain level. Without fertilizers, the grain yield was $1.5 \mathrm{t} / \mathrm{ha}$, profit $-2,309 \mathrm{rub} / \mathrm{ha}$, profitability $-28 \%$. The use of fertilizers at a dose of r.a. on average $18 \mathrm{~kg} / \mathrm{ha}$ increased the yield to $1.8 \mathrm{t} / \mathrm{ha}$, profit - to $3,830 \mathrm{rub} / \mathrm{ha}$, profitability - to $43 \%$. At $48 \mathrm{~kg}$ r.a./ha, the yield and profit increased, but there was no increase in profitability (Table 2).

Table 2. The impact of fertilizers on the efficiency of grain production in agricultural enterprises of the Kurgan region, 2019.

\begin{tabular}{|l|c|c|c|}
\hline \multirow{2}{*}{ Production indicators } & \multicolumn{3}{c|}{$\begin{array}{c}\text { Value of indicators in enterprise groups } \\
\text { with different level of fertilizer application }\end{array}$} \\
\cline { 2 - 4 } & 1 & 2 & 3 \\
\hline $\begin{array}{l}\text { Dose of the active substance of } \\
\text { fertilizers, } \mathrm{kg} / \mathrm{ha}\end{array}$ & $\mathbf{0}$ & $\mathbf{1 8}$ & $\mathbf{4 8}$ \\
\hline Yield, $\mathrm{t} / \mathrm{ha}$ & 1.5 & 1.8 & 2.4 \\
\hline Profit, rub/ha & 2309 & 3830 & 6290 \\
\hline Profitability, \% & 28 & 43 & 43 \\
\hline
\end{tabular}

Among the influencing factors from the elements of agricultural technologies, the method of tillage is of great economic and agronomic importance. In the Kurgan region, over the past 10-15 years, there has been a significant expansion of sown areas with minimal or zero soil tillage: according to the Department of Agriculture of the region, deep dump and non-fallow plowing is carried out only on $7-10 \%$ of the cultivated areas, surface 
treatment is $40-45 \%$ (including $23-26 \%$ mechanical steam with surface treatment), stubble crops are $48-53 \%$ (including 5\% for chemical fallow). According to the research of the Kurgan Research Institute of Agricultural Sciences, conducted on the leached mediumloamy chernozem of the central forest-steppe zone of the Trans-Urals, the system of combined tillage in a fallow field with the use of chemical agents and mechanical techniques allowed to conduct more profitable production of high-quality spring wheat grain in comparison with classical and zero technologies [11].

The analysis of agricultural reports of agricultural enterprises showed a weak connection between the profitability of production and the tillage methods. At the same time, there is a tendency of higher efficiency of grain crops sown in pairs and in autumn processing compared to the stubble background. With an increase in the share of sowing for fallow from $28 \%$ to $32 \%$, for autumn processing from $31 \%$ to $36 \%$ and a decrease in stubble crops from $42 \%$ to $32 \%$, the yield increased from 1.7 to $2.0 \mathrm{t} /$ ha, profitability from 8 to $34 \%$ (Table 3). Of the methods of autumn processing in the 3rd group, surface processing prevailed (from 62 to $87 \%$ ), the change in its share did not have a noticeable effect on production efficiency. According to the methods of fallow preparation, the share of chemical (or combined) fallow in the third group increased from $11 \%$ to $39 \%$ compared to the second.

The weak statistical relation between the types of tillage and the effectiveness of technologies indicates the possibility of obtaining high results in different ways, as well as the effectiveness and unprofitability of the same agricultural practices in different natural and organizational conditions, which indicates the stage of agriculture development associated with a differentiated approach to the introduction of agricultural technologies. High results in farms are achieved due to high-quality and accurate implementation of all elements of technologies, which is largely provided by qualified and, importantly, modern (digital) management methods: satellite monitoring of equipment, electronic field maps, a differentiated approach is used to identify reserves for saving resources.

Table 3. The efficiency of grain production and the use of different types of tillage in agricultural enterprises of the Kurgan region, 2019.

\begin{tabular}{|c|c|c|c|c|}
\hline \multirow{2}{*}{\multicolumn{2}{|c|}{ Production indicators }} & \multicolumn{3}{|c|}{ Profitability group } \\
\hline & & 1 & 2 & 3 \\
\hline \multicolumn{2}{|l|}{ Profitability, \% } & 8 & 34 & 68 \\
\hline \multicolumn{2}{|l|}{ Yield, t/ha } & 1.7 & 2.0 & 2.1 \\
\hline \multicolumn{2}{|l|}{ Profit, rub/ha } & 841 & 4829 & 6708 \\
\hline \multicolumn{2}{|l|}{ Cost price, rub/c } & 648 & 621 & 598 \\
\hline \multicolumn{2}{|l|}{ Costs, rub/ha } & 10997 & 12172 & 12658 \\
\hline \multirow{3}{*}{$\begin{array}{l}\text { Placement of } \\
\text { sowings, } \%\end{array}$} & for fallow & 28 & 32 & 33 \\
\hline & for autumn treatment & 31 & 36 & 35 \\
\hline & for stubble & 42 & 32 & 32 \\
\hline \multirow{3}{*}{$\begin{array}{l}\text { Method of autumn } \\
\text { soil treatment, \% }\end{array}$} & dump & 13 & 29 & 18 \\
\hline & beardless & 2 & 10 & 4 \\
\hline & surface & 86 & 62 & 77 \\
\hline \multirow{2}{*}{$\begin{array}{c}\text { Method of } \\
\text { fallow preparation, } \\
\%\end{array}$} & mechanical & 73 & 89 & 61 \\
\hline & $\begin{array}{l}\text { chemical, } \\
\text { combined }\end{array}$ & 27 & 11 & 39 \\
\hline
\end{tabular}

So, for example, when using fertilizers, an important reserve for their reasonable saving can be the clarification of the dose of r.a. in each field, and in the future, at each microstage. To calculate differentiated doses of fertilizers, it is necessary to choose the most optimal calculation method with further verification of its correctness in the conditions of the field or plot, as suggested by the authors of the article [12]. The Kurgan Research 
Institute of Agricultural Sciences has proposed its own method for calculating the doses of nitrogen fertilizers depending on the eight most significant factors [13].

It should be noted that an approach differentiated for each field or site requires information about each field, which involves maintaining field history books - the initial basic stage of the production data system, the result of strategic decision-making depends on the completeness and quality of information. Given the imperfection of obtaining information from agricultural reports, it is necessary to create a digital information database of production data. Both at the federal and regional levels, similar geoinformation systems have already been developed that allow linking data about fields to their coordinates on an electronic map. Nevertheless, there are still serious problems with filling in this information due to the lack of specialists to collect information. Therefore, it is necessary that the electronic databases of the field history are in the enterprise. It is fundamentally important to create them as early as possible to analyze the years that differ in weather conditions and technologies.

Using the example of the production fields of the Kurgan Research Institute of Agricultural Sciences, the authors of the article have been collecting and systematizing agronomic information for each field in an electronic database under the control of their own program "Managing the electronic database of the state and functioning of agricultural landscapes" since 2017. Maintaining the history of fields allows not only to systematize information, but also to analyze any parameters of agricultural technologies used in the economy, to further calculate the economic efficiency for each field.

For example, in 2017-2020, it was possible to note fields with different yields with different methods of sowing (and, accordingly, the method of soil preparation), precursors and fertilization (Table 4). The spring wheat variety Raduga is taken as an example. On average, in 4 years, the advantage of the fallow precursor is visible. A disk seeder for fallow was used, as a rule, for early sowing, but in all cases the yield compared to a stubble seeder on the same background of processing differed slightly with a slight advantage in SZ-5.4. Stubble crops were inferior in yield in all years, but in the dry 2020, late stubble crops turned out to be more productive. These conclusions allow to confidently use both types of seeders and the advantage of stubble backgrounds and late sowing dates in dry years.

Table 4. The yield of spring wheat of the Raduga variety in the fields of the Kurgan Research Institute of Agricultural Studies, $\mathrm{t} / \mathrm{ha}$.

\begin{tabular}{|c|c|c|c|}
\hline \multirow{2}{*}{$\begin{array}{c}\text { Year } \\
\text { (HTC May- } \\
\text { August) }\end{array}$} & \multicolumn{2}{|c|}{ For surface fallow (N0) } & $\begin{array}{c}\text { For wheat without autumn } \\
\text { tillage with fertilizer (N40) }\end{array}$ \\
\cline { 2 - 4 } & $\begin{array}{c}\text { sowing period / seeder } \\
\text { SZ-5,4 }\end{array}$ & $\begin{array}{c}\text { sowing period / seeder } \\
\text { SKP-2,1 }\end{array}$ & $\begin{array}{c}\text { sowing period / seeder SKP- } \\
2,1\end{array}$ \\
\hline $2017(1.0)$ & May 4 / 3.77 & May 18 / 3.57 & May 14 $/ 2.80$ \\
\hline $2018(0.9)$ & May 13/ 2.81 & May 15/2.73 & May 19/1.93 \\
\hline $2019(0.9)$ & May 04/2.24 & May 17/2.46 & - \\
\hline $2020(0.5)$ & May 01 / 1.29 & May 15/1.09 & May 25/1.31 \\
\hline Average & 2.53 & 2.46 & 2.01 \\
\hline
\end{tabular}

Nevertheless, the complexity of the analysis of production data lies in their multifactorial nature and in the fact that there is practically no principle of a single difference in them. At the same time, it is on their basis that the conclusion is made about the effectiveness of the introduction of agricultural practices in production on the scale of not only the economy, but also the region. In this regard, it is important to compare the data as correctly as possible, trying to distinguish groups of fields by the most significant factors: the precursor, the sowing period, the variety, the type of soil, the infestation of the field, and others. 
When accumulating a large amount of data, analytics should be carried out using computer programs that allow selecting the most significant information for decisionmaking from an array of heterogeneous information. The methodology of such a systemcognitive analysis and the software that implements it were developed at the Kuban SAU of V.E. Lutsenko [14]. To varying degrees, the analysis of production data is implemented in some GIS transport monitoring systems. Nevertheless, it is the collection and analysis of production data by the agronomic service that is now a priority task in agricultural enterprises, without which further analysis and search for reserves for improving the efficiency of agricultural technologies will be impossible.

\section{Conclusions}

Thus, when the costs of intensification increase, to maintain profitable production, it is important to identify internal savings reserves based on the analysis of production data that affect the effectiveness of agricultural technologies.

Agricultural enterprises have information that is contained in accounting and agronomic reports and shows the possibility of obtaining high results in agriculture with various technologies. The analysis of production reports showed that the efficiency of technologies in the Trans-Urals is increased by the use of optimal doses of fertilizers, the choice of crop rotations with fallow field. Reserves of profitability growth in a separate farm are associated with a more accurate use of resources, which is possible when maintaining field history books, electronic versions of which allow to store and quickly extract any stored information into reports for further economic analysis and design of farming systems

\section{References}

1. Kh.L. Bogotov, R.A. Karezhev, A. M. Podlinova, Achievements of modern science, 4(3), 139-141 (2017)

2. L.G. Matveeva, A.Yu. Nikitaeva, O.A. Chernova, Terra Economicus 16(1), 134-145 (2018) DOI: 10.23683/2073-6606-2018-16-1-134-145

3. V.I. Medennikov, Chronoeconomics 5 (26), 12-17 (2020)

4. A.I. Altukhov, A.V. Bogoviz, I.M. Kuznetsov, Advances in Intelligent Systems and Computing 726, 800-809 (2019) DOI: 10.1007/978-3-319-90835-9_92

5. V.I. Medennikov, International Agricultural Journal 2 (380), 48-51 (2021) DOI: 10.24412/2587-6740-2021-2-48-51

6. F.I. Ereshko, V.V. Kulba, V.I. Medennikov, Agro-industrial complex: economics, management 10, 34-46. (2018)

7. S.O. Siptits, I.A. Ganieva, I.A. Romanenko, N.E. Evdokimova, Amazonia Investiga 8, 24, 500-508 (2019)

8. F.I. Ereshko, V.I. Medennikov, L.V. Bogatyreva, System analysis of the problems of the digital economy and the formation of digital platforms. Managing the development of large-scale systems (MLSD'2019). Proceedings of the Twelfth International Conference, 220-230 (2019)

9. V.I. Kiryushin, S.V. Kiryushin, Agrotechnologies: Textbook, (St. Petersburg: Publishing house "Lan", 2015)

10. D.A. Zyukin, International Agricultural Journal 6, 42-45 (2018) DOI: 10.24411/25876740-2018-16093 
11. S.D. Gilev, I.N. Tsymbalenko, A.N. Kopylov, Yu.V. Surkova, V.P. Efremov, Agrochemistry 3, 49-54 (2020)

12. N.I. Akanova, L.B. Vinnichek, V.Yu. Zhdanov, M.M. Vizirskaya, I.Yu. Zhdanov, International Agricultural Journal 2, 85-88 (2020) DOI: 10.24411/2587-6740-202012038

13. N.V. Stepnykh, A. N. Kopylov, E. V. Nesterova, A. M. Zargaryan, Agrochemistry 4, 19-29 (2020)

14. E.V. Lutsenko, Universal cognitive analytical system "Eidos". Monograph (scientific publication) (Krasnodar: KubSAU, 2014) 